\title{
Hypertension in Nigerian children
}

\author{
W. I. ADERELE and O. SERIKI \\ From the Department of Paediatrics, University College Hospital, Ibadan, Nigeria
}

Aderele, W. I., and Seriki, O. (1974). Archives of Disease in Childhood, 49, 313. Hypertension in Nigerian children. A retrospective review of 138 cases of hypertension in Nigerian children attending the University College Hospital, Ibadan, during a 9-year period was undertaken. The main findings were (a) that hypertension occurs more commonly in children aged 5 to 10 years and is seen in both sexes; (b) that nephrotic syndrome is the most frequent clinical condition associated with hypertension in these children; (c) that glomerulonephritis is the most frequent histological finding at biopsy or necropsy; (d) that unlike the experience in Europe and America, pyelonephritis is not a major cause of hypertension in Nigerian children; (e) that the course of hypertension in the majority of the children is rapidly progressive and prognosis is poor.

It is now well recognized, contrary to the views held in the past (Donnison, 1929; Jex-Blake, 1934; Vint, 1937), that essential hypertension does exist in the African. There have been many reports on various aspects of hypertension in the African adult (Abrahams and Alele, 1960; Somers, 1960; Smith, 1966; Akinkugbe, 1972) and in non-African children (Haggerty, Maroney, and Nadas, 1956; Still and Cottom, 1967), but as far as we know there has been little written about hypertension in African children. Recently, a large number of children presented with hypertension at our hospital and this has led us to review cases of hypertension in children attending the paediatric department at this hospital over the 9-year period, January 1964 to December 1972.

\section{Materials and method}

In order to establish the normal range of blood pressure in Nigerian children, the pressure was measured in 100 normal children, aged 2 to 11 years, attending the outpatient clinics.

For the purpose of this review, hypertension is defined as a sustained diastolic blood pressure of $90 \mathrm{mmHg}$ or above. All children found to be hypertensive in the outpatient clinics or on admission to the wards according to definition have been included. Those with only one reading above this level have been excluded. The usual investigations included urine analysis, electrolytes, and urea, serum creatinine, chest $x$-rays, electrocardiography, and intravenous pyelography. Renal biopsies, protein selectivity (carried out by Dr. A. Adeniyi), and aortography were done in selected cases. The aetiological diagnosis was based on the history, physical findings, investigations, and biopsy or necropsy findings.

Received 19 September 1973.

\section{Results}

The blood pressure readings in 100 normal Nigerian children, aged 2 to 11 years, are presented in Table I. It can be seen that a diastolic level of 80 $\mathrm{mmHg}$ is the upper limit of normal for this group of apparently normal children up to the age of 11 years.

During the period covered in this review, there were 138 cases of hypertension representing an average of 15 patients per year. 65 of these were males and 73 were females. The number of children with hypertension has increased over the years. This increase has paralleled the increase of paediatric patients seen in the hospital. It also reflects the increase in the number of children with nephrotic syndrome.

The frequency of hypertension in relation to age

TABLE I

Blood pressure readings in 100 normal Nigerian children attending the outpatient clinics

\begin{tabular}{l|cc|c}
\hline $\begin{array}{c}\text { Age group } \\
\text { (yr) }\end{array}$ & $\begin{array}{c}\text { No. of } \\
\text { subjects }\end{array}$ & $\begin{array}{c}\text { Systolic blood } \\
\text { pressure (mmHg) }\end{array}$ & $\begin{array}{c}\text { Diastolic blood } \\
\text { pressure (mmHg) }\end{array}$ \\
\hline $\begin{array}{c}\text { p-3 } \\
\text { Average }\end{array}$ & 20 & 86 & 56 \\
SD & & 10 & 10 \\
Range & & $70-100$ & $40-70$ \\
$3-7$ & 50 & 89 & 55 \\
$\begin{array}{l}\text { Average } \\
\text { SD }\end{array}$ & & 15 & 14 \\
Range & & $60-120$ & $30-80$ \\
$7-11$ & 30 & 95 & 58 \\
Average & & 12 & 12 \\
SD & & $70-120$ & $35-80$ \\
Range & & & \\
\hline
\end{tabular}


groups (Fig.) shows that the majority of the patients were in the 5- to 10-year age group. It should also be noted that $32(23 \%)$ of the total number were under 5 years of age.

Clinical presentations. The mode of presentation in 138 cases is shown in Table II. In a majority of the cases the hypertension was discovered on routine physical examination of patients attending the nephrology clinic or the general paediatric clinics with various complaints including heart failure, anaemia, hemiplegia, and convulsion. In 36 patients the hypertension was a feature of acute glomerulonephritis. 30 patients presented with uraemia and 20 with severe anaemia. Many who presented with uraemia were also found to be anaemic. 19 children were in heart failure at first visit. 9 children presented with hypertensive encephalopathy and 2 of these had papilloedema. 5 patients presented in various other ways.

The average blood pressure at which encephalopathy developed was $180 / 130 \mathrm{mmHg}$ (range 150/110 to $260 / 190 \mathrm{mmHg}$ ). 4 patients (44\%) with

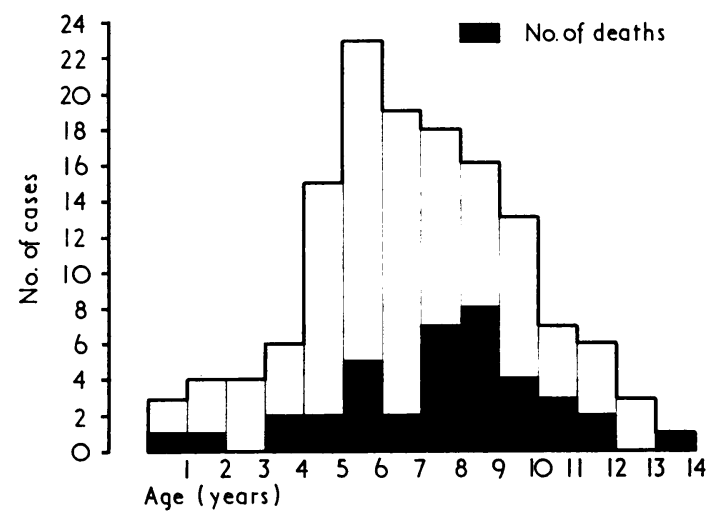

FIG.-Hypertension. Age at presentation and mortality.
TABLE II

Mode of presentation in 138 cases of hypertension

\begin{tabular}{l|c}
\hline \multicolumn{1}{c|}{ Mode of presentation } & No. of cases \\
\hline $\begin{array}{l}\text { Hypertension discovered on routine } \\
\text { examination }\end{array}$ & 73 \\
Hypertension associated with acute & \\
glomerulonephritis & 36 \\
Uraemia & 30 \\
Anaemia & 20 \\
Heart failure & 19 \\
Encephalopathy & 9 \\
Miscellaneous & \\
$\quad$ Leukaemia 1, hydronephrosis 1, & \\
haemolytic-uraemic syndrome 1, & \\
nephroblastoma 1, haematuria 1 & 5 \\
\hline
\end{tabular}

encephalopathy survived, while 2 of these remained hemiplegic.

Aetiology. Table III shows the aetiological diagnosis in the 138 children.

Glomerulonephritis. There were 36 cases of acute glomerulonephritis; 7 of these later developed the nephrotic syndrome with persisting hypertension, while 28 became normotensive within 40 days of the onset of hypertension. The remaining patient died during the acute phase of the illness. There were 27 cases of subacute and chronic glomerulonephritis that presented as cases of nephrotic syndrome or chronic renal failure.

Nephrotic syndrome. 60 cases of hypertension occurred in children with the nephrotic syndrome. 36 of these children had received steroids before the onset of hypertension. Biopsies were carried out in $\mathbf{4 5}$ patients in this group and the histology revealed various forms of glomerulonephritis, the commonest type being localized or diffuse thickening of the capillary wall which later progresses to complete sclerosis. Membranous and

TABLE III

Aetiology of hypertension in 138 children

\begin{tabular}{|c|c|c|c|c|}
\hline & Male & Female & Total & $\%$ of total \\
\hline $\begin{array}{l}\text { Acute glomerulonephritis } \\
\text { Subacute and chronic glomerulonephritis } \\
\text { Nephrotic syndrome } \\
\text { Nephrotic syndrome treated with steroids } \\
\text { Renovascular } \\
\text { Pyelonephritis } \\
\text { Undetermined } \\
\text { Miscellaneous-hydronephrosis, steroid therapy only, } \\
\text { haemolytic-uraemic syndrome, nephroblastoma }\end{array}$ & $\begin{array}{r}18 \\
13 \\
8 \\
16 \\
1 \\
1 \\
5\end{array}$ & $\begin{array}{r}18 \\
14 \\
16 \\
20 \\
2 \\
1 \\
1 \\
1\end{array}$ & $\begin{array}{r}36 \\
27 \\
24 \\
36 \\
3 \\
2 \\
6 \\
\end{array}$ & $\begin{array}{r}26 \cdot 0 \\
20 \cdot 0 \\
17 \cdot 0 \\
26 \cdot 0 \\
2 \cdot 2 \\
1 \cdot 5 \\
4 \cdot 4 \\
2 \cdot 9\end{array}$ \\
\hline Total & 65 & 73 & 138 & $100 \cdot 0$ \\
\hline
\end{tabular}


membrano-proliferative changes are the next common lesions.

There were 36 cases with the nephrotic syndrome who had received prednisolone before the onset of hypertension. $10(28 \%)$ of these died while 22 became normotensive within 2 months of withdrawing steroid. 1 hypertensive patient is still attending the clinic while 3 others, still hypertensive, have left the clinic.

There was one other case of prednisolone-induced hypertension in a 6-year-old boy admitted with acute lymphoblastic leukaemia, who developed hypertension 2 days after completing a 5-week course of prednisolone. 3 weeks later he became normotensive and remained so without specific antihypertensive drug therapy.

Renovascular. There were 3 cases with renovascular abnormalities shown by aortography in all 3 and confirmed at necropsy in 1. This 9-yearold girl was found to have a generalized arterial disease including a left renal artery stenosis, abdominal aortitis with calcification, and a left renal atrophy. (Details of this case will be reported later.)

Pyelonephritis. Hypertension occurred in only 2 cases of pyelonephritis. The record showed that of the 79 available reports on these cases, 22 gave positive urine cultures. 20 became negative on further examination. In all these 22 cases the intravenous pyelograms were normal.

Miscellaneous. There was a case each of hypertension due to hydronephrosis, haemolyticuraemic syndrome, and nephroblastoma. There were 6 cases of hypertension of unknown aetiology. 5 of these children presented with heart failure and albuminuria.

Severity of hypertension (Table IV). The patients were divided into three clinical categories of severity according to the level of diastolic pressure: severe, pressure above $120 \mathrm{mmHg}$; moderate,
TABLE IV

Mortality in relation to severity of hypertension

\begin{tabular}{l|c|c|c}
\hline Severity & $\begin{array}{c}\text { Diastolic blood } \\
\text { pressure (mmHg) }\end{array}$ & Total no. & $\begin{array}{c}\text { No. of deaths } \\
\text { (and \%) }\end{array}$ \\
\hline Severe & $<120$ & 22 & $14(64)$ \\
Moderate & $100-120$ & 90 & $18(20)$ \\
Mild & $90-100$ & 26 & $6(23)$ \\
\hline
\end{tabular}

pressure from 100 to $120 \mathrm{mmHg}$; and mild, pressure 90 to $100 \mathrm{mmHg}$. Of the 138 cases, there were 22 ( 11 males and 11 females) with severe hypertension, 90 (45 males and 45 females) with moderate hypertension, and 26 ( 9 males and 17 females) with mild hypertension. Table $\mathrm{V}$ summarizes the causes in 22 patients with severe hypertension. It will be observed that severe hypertension was associated with the nephrotic syndrome in $50 \%$ of the cases (32\% of those treated with steroids and $18 \%$ without) while in $50 \%$ it was associated with glomerulonephritis.

Management. Specific antihypertensive drugs (methyldopa, hydrallazine, guanethidine) were used on 68 patients with either nephrotic syndrome or chronic renal failure. Reserpine was used on those patients with acute glomerulonephritis. In addition to the specific antihypertensive drugs, all patients with encephalopathy received magnesium sulphate. Remission of the hypertension followed nephrestomy in 1 patient who had nephroblastoma.

Prognosis. The outcome for the 138 patients is summarized in Table VI, showing that $38(27.5 \%)$ patients died, 17 males and 21 females. The average interval between the detection of hypertension and death was 16 weeks (range 1 day to 30 months). Necropsy was performed in 21 (55\%) and the findings were chronic glomerulonephritis 12 , subacute glomerulonephritis 4, acute glomerulonephritis 1, pyelonephritis 1 , hydronephrosis 1 , aortitis, renal artery stenosis, and atrophied left kidney 1 , unknown 1 .

TABLE V

Aetiology of severe hypertension (diastolic pressure $>120 \mathrm{~mm} \mathrm{Hg}$ ) in 22 children

\begin{tabular}{|c|c|c|c|c|}
\hline & Male & Female & Total & $\%$ of total \\
\hline $\begin{array}{l}\text { Nephrotic syndrome treated with steroids } \\
\text { Acute glomerulonephritis } \\
\text { Subacute and chronic glomerulonephritis } \\
\text { Nephrotic syndrome }\end{array}$ & $\begin{array}{l}4 \\
1 \\
2 \\
4\end{array}$ & $\begin{array}{l}3 \\
5 \\
3 \\
0\end{array}$ & $\begin{array}{l}7 \\
6 \\
5 \\
4\end{array}$ & $\begin{array}{l}32 \\
27 \\
23 \\
18\end{array}$ \\
\hline Total & 11 & 11 & 22 & 100 \\
\hline
\end{tabular}


TABLE VI

Prognosis in 138 cases of hypertension

\begin{tabular}{l|c}
\hline \multicolumn{1}{c|}{ Prognosis } & No. of patients (and \%) \\
\hline Died & $38(28)$ \\
Normotensive when last seen & $82(59)$ \\
Still attending with hypertension & $6(4)$ \\
Still hypertensive when lost to & $12(9)$ \\
follow-up & \\
\hline
\end{tabular}

\section{Discussion}

Diagnosis of hypertension in anyone depends on a knowledge of the normal range of blood pressure for the age and sex of that individual. From published figures (Robinson and Brucer, 1939; Nadas, 1963; Londe, 1966; Londe et al., 1971) and from the levels obtained during routine blood pressure measurement in apparently normal Nigerian children attending the children's clinic by one of the authors (Table I), it is evident that the diastolic level of 80 $\mathrm{mmHg}$ is the upper limit of normal up to the age of 11 years.

There is no doubt that hypertension exists in African children as elsewhere. In this series, renal lesions account for the vast majority. The highest incidence is in the age group 5 to 10 years. Still and Cottom (1967), reporting a total of 55 children with severe hypartension, found that the cases were distributed over ages 1 to 14 years, but that there were more cases in the older age group. The great majority of the children in our serits had glomerulonephritis and presented as nephrotic syndrome. There were 73 females to 65 males giving a sex ratio of $1 \cdot 1: 1$. This slight female preponderance is a reflection of the number of female nephrotic children in the group. There was no sex difference in the series reported by Still and Cottom (1967).

Our results have shown that various forms of glomerulonephritis account for $63 \%$ of the cases of hypertension. This figure does not include cases of nephrotic syndrome with probable glomerulonephritis who had been treated with steroid (prednisolone). This figure contrasts sharply with that of Still and Cottom (1967), but is in keeping with results obtained elsewhere (McCrory and Nash, 1952; Loggie, 1969, 1971). Still and Cottom (1967) found that pyelonephritis (primary and secondary) was responsible for $59 \%$ of their cases and only $11 \%$ were caused by glomerulonephritis. This significant difference may be due to the fact that many of our cases developed hypertension during follow-up in the nephrology clinic, while in their series acute glomerulonephritis with temporary hypertension had been excluded.
The use of steroid (prednisolone) in the treatment of nephrotic syndrome in our children was followed by the development of hypertension in 36 children $(26 \%)$. This adverse response to steroid is much more noticeable in our children than in the temperate countries (Cameron, 1968). The reason for this difference is quite clear. The majority of our children have Plasmodium malariae nephropathy which is known to respond poorly to steroid and to lead readily to hypertension (Hendrickse et al., 1972; Adeniyi, Hendrickse, and Houba, 1970; Adeniyi, 1971). This finding suggests that steroid is contraindicated in $90 \%$ or more of children with nephrotic syndrome in Nigeria.

There are only 2 cases of hypertension due to chronic pyelonephritis in this series. This finding is different from experience elsewhere. Urinary tract infections do occur in the children seen in this hospital, but the condition is less common than acute glomerulonephritis and even much less common than the nephrotic syndrome. Furthermore, the chronic stage of pyelonephritis is difficult to differentiate from chronic glomerulonephritis.

Attention has been drawn by Akinkugbe (1972) to the rarity of papilloedema in the African with severe hypertension, and in our 22 cases with severe hypertension only $2(9 \%)$ showed papilloedema. On the other hand, 20 of the 55 cases $(36 \%)$ reported by Still and Cottom (1967) had papilloedema. The reason for this difference is not clear. There is speculation that racial and dietary factors are important. This important difference deserves further study.

The occurrence of hypertension in association with nephroblastoma (Wilms's tumour) is well recognized (Koons and Ruch, 1940; Hughes, Rosenblum, and Horn, 1949; Nwako and Ibekwe, 1973). The experience in this hospital is that hypertension is an uncommon feature of Wilms's tumour.

There was one case of hypertension in association with haemolytic-uraemic syndrome in which the child's hypertension was transient and returned to normal with recovery of the acute renal condition. Previous reports (Gianantonio et al., 1964; Moorhead, Edwards, and Goldsmith, 1965) have indicated that hypertension does occur in the haemolytic-uraemic syndrome, but it is not a constant feature. In the series reported by Gianantonio et al., hypertension was noted in 32 patients; in 13 of these it was transient, while in the remaining 19 it was more prolonged or did not appear until one week from the onset of oliguria.

In this series there were 6 children $(5$ males and 1 female) aged 3, 10, 17, and 18 months, and 7 and 8 
years, respectively, in whom no cause was found for the hypertension. 2 of these presented as bronchopneumonia and heart failure, 3 as congestive heart failure, and the remaining 1 with convulsion and anuria. Initial blood pressure varied between $110 / 90$ and 160/110. Hypertension was present for only 3 weeks in 1 of these children and he recovered completely. 2 died, but necropsy carried out in 1 showed only bronchopneumonia and ileitis. The kidney was macroscopically normal. Death in these 2 cases was probably unrelated to the hypertension. Essential hypertension has been recorded in juveniles aged 14 years and over (Kuramoto et al., 1968), but all the children in this series were 14 years or less and the hypertension in these 2 cases could not be labelled essential hypertension.

The management of hypertension in these children is based on the principle of finding the cause of the hypertension and treating the cause when it is known. When no cause can be found the treatment is directed to the control of hypertension by the usual drugs such as diuretics and the commonly employed antihypertensive drugs. In many of the children in this series hypertension developed as a complication of known renal lesions. Unfortunately, these lesions are progressive and are not influenced by known regimens including steroids and immunosuppressive drugs. In fact the treatment of these children with steroid is contraindicated except in very few selected cases. Therefore, instead of treating the complication of the renal lesions, effort should be directed to the prevention by malaria control and early detection of nephrotic syndrome in the 3- to 5-year age group.

We acknowledge with thanks the permission of the consultant staff of the Department of Paediatrics, University College Hospital, Ibadan, to include their patients in this review; and thank Dr. A. Adeniyi, who carried out protein selectivity tests and biopsy on many of the patients. We also thank Professor A. U. Antia for his helpful criticism; Mr. S. A. Olaleye, Confidential Secretary, for assistance; and the Medical Records Staff for co-operation.

\section{REFERENCES}

Abrahams, D. G., and Alele, C. A. (1960). Clinical study of hypertensive disease in West Africa. West African Medical fournal, 9, 183.

Adeniyi, A. (1971). Nephrotic syndrome in Nigerian children. M.D. Thesis. University of London.

Adeniyi, A., Hendrickse, R. G., and Houba, V. (1970). Selectivity of proteinuria and response to prednisolone or immuno- suppressive drugs in children with malarial nephrosis. Lancet, 1,644 .

Akinkugbe, O. O. (1972). High Blood Pressure in the African, p. 94. Churchill Livingstone, Edinburgh and London.

Cameron, J. S. (1968). Histology, protein clearances, and response to treatment in the nephrotic syndrome. British Medical fournal, 4, 352.

Donnison, C. P. (1929). Blood pressure in the African native. Lancet, 1, 6.

Gianantonio, C., Vitacco, M., Mendilaharzu, F., Rutty, A., and Mendilaharzu, J. (1964). The hemolytic-uremic syndrome. fournal of Pediatrics, 64, 478.

Haggerty, R. J., Maroney, M. W., and Nadas, A. S. (1956). Essential hypertension in infancy and childhood; differential diagnosis and therapy. American fournal of Diseases of Children, 92,535 .

Hendrickse, R. G., Glasgow, E. F., Adeniyi, A., White, R. H. R., Edington, G. M., and Houba, V. (1972). Quartan malarial nephrotic syndrome-collaborative clinicopathological study in Nigerian children. Lancet, 1, 1143.

Hughes, J. G., Rosenblum, H., and Horn, L. G. (1949). Hypertension in embryoma (Wilms' tumour). Pediatrics, 3, 201.

Jex-Blake, A. J. (1934). High blood pressure. East African Medical fournal, 10, 286.

Koons, K. M., and Ruch, M. K. (1940). Hypertension in a 7-year old girl with Wilms' tumor relieved by nephrectomy. fournal of the American Medical Association, 115, 1097.

Kuramoto, K., Murata, K., Yazaki, Y., Ikeda, M., and Nakao, K. (1968). Hemodynamics in juvenile hypertension with special reference to the response to propanolol. Fapanese Circulation fournal, 32, 981.

Loggie, J. M. H. (1969). Hypertension in children and adolescents, causes and diagnostic studies. Fournal of Pediatrics, 74, 331.

Loggie, J. M. H. (1971). Systemic hypertension in children and adolescents: causes and treatment. Pediatric Clinics of North America, 18, 1273.

Londe, $S$. (1966). Blood pressure in children as determined under office conditions. Clinical Pediatrics, 5, 71.

Londe, S., Bourgoignie, J. J., Robson, A. M., and Goldring, D. (1971). Hypertension in apparently normal children. Fournal of Pediatrics, 78, 569 .

McCrory, W. W., and Nash, F. W. (1952). Hypertension in children; a review. American fournal of the Medical Sciences, 223,671 .

Moorhead, J. F., Edwards, E. C., and Goldsmith, H. J. (1965). Haemodialysis of three children and one infant with a haemolytic-uraemic syndrome. Lancet, 1, 570.

Nadas, A. S. (1963). Pediatric Cardiology, 2nd ed., p. 773. Saunders, Philadelphia.

Nwako, F. A., and Ibekwe, O. (1973). The Wilms' tumour-old and new facts. I. Clinical features and tumour biology. West African Medical fournal, 22, 26.

Robinson, S. C., and Brucer, M. (1939). Range of normal blood pressure: a statistical and clinical study of 11,383 persons. Archives of Internal Medicine, 64, 409.

Smith, A. J. (1966). Arterial hypertension in the Lagos University Teaching Hospital. West African Medical fournal, 15, 97.

Somers, K. (1960). Hypertension and its management in an African Hospital in Uganda. Fournal of Tropical Medicine and Hygiene, 63, 260.

Still, J. L., and Cottom, D. (1967). Severe hypertension in childhood. Archives of Disease in Childhood, 42, 34.

Vint, F. W. (1937). Post-mortem findings in the natives of Kenya. East African Medical fournal, 13, 332.

Correspondence to Dr. O. Seriki, Department of Paediatrics, University College Hospital, Ibadan, Nigeria. 